\title{
NÚMERO DE CASOS CONFIRMADOS DE MENINGITE NO BRASIL NO PERÍODO DE 2011 A 2015
}

\author{
ARTIGO ORIGINAL \\ MATOS, Alex Costa ${ }^{1}$ \\ FECURY, Amanda Alves ${ }^{2}$ \\ OLIVEIRA, Euzébio ${ }^{3}$ \\ DENDASCK, Carla Viana ${ }^{4}$
}

DIAS, Cláudio Alberto Gellis de Mattos ${ }^{5}$

MATOS, Alex Costa. Et al. Número de casos confirmados de meningite no Brasil no período de 2011 a 2015. Revista Científica Multidisciplinar Núcleo do Conhecimento. Ano 05, Ed. 05, Vol. 01, pp. 121-130. Maio de 2020. ISSN: 2448-0959, Link de acesso: https://www.nucleodoconhecimento.com.br/saude/meningite-nobrasil, DOI: 10.32749/nucleodoconhecimento.com.br/saude/meningite-no-brasil

\footnotetext{
1 Técnico em mineração pelo Instituto de Ensino Básico, Técnico e tecnológico do Amapá (IFAP).

2 Biomédica, Doutora em Doenças Topicais, Professora e pesquisadora do Curso de Medicina do Campus Macapá, Universidade Federal do Amapá (UNIFAP).

3 Biólogo, Doutor em Doenças Topicais, Professor e pesquisador do Curso de Educação Física da, Universidade Federal do Pará (UFPA).

${ }^{4}$ Teóloga, Doutora em Psicanálise, pesquisadora do Centro de Pesquisa e Estudos Avançados- CEPA.

${ }^{5}$ Biólogo, Doutor em Teoria e Pesquisa do Comportamento, Professor e pesquisador do Curso de Licenciatura em Química do Instituto de Ensino Básico, Técnico e tecnológico do Amapá (IFAP).
} 


\section{RESUMO}

Meningite é a infecção das meninges que envolvem o encéfalo e a medula espinhal, podendo ser causada por diferentes microrganismos como bactérias, fungos ou organismos acelulares (vírus). A meningite causada por bactérias pode ter como sintomas febre, rigidez da nuca, náusea, vômitos, fotofobia, cefaleia, agitação e convulsão. Este trabalho pretendeu mostrar o número de casos confirmados de Meningite no Brasil, quanto ao ano, região de notificação, faixa etária, sexo e raça no período de 2011 a 2015. A pesquisa quantitativa foi realizada no banco de dados do DATASUS[7]. Os casos confirmados de meningite no Brasil em 2015, diminuíram devido a campanhas de prevenções e higiene promovidas pelo governo federal, com auxílio de campanhas de vacinação. O Sudeste, por ser a região mais populosa do Brasil, teve maior número de casos confirmados devido à grande concentração de indivíduos que convivem nos mesmos ambientes dentro da sociedade. Isso faz o agente causador da doença se espalhe de maneira mais dinâmica. As crianças e jovens foram as pessoas mais afetadas pela meningite por ficarem em um grande período de tempo dentro de ambientes escolares com grande aglomeração de indivíduos.

Palavras-Chave: Meningite, epidemiologia, infecção.

\section{INTRODUÇÃO}

As meninges são camadas de tecidos finos que envolvem a parte superior e a alongada do sistema nervoso central, onde estão localizados o encéfalo e a medula espinhal (POBB et al., 2013).

Meningite é a infecção das meninges que envolvem o encéfalo e a medula espinhal, podendo ser causada por diferentes microrganismos como bactérias, fungos ou organismos acelulares (vírus) (POBB et al., 2013).

A transmissão se dá através do contato prolongado com secreções respiratórias de pessoas infectadas (POBB et al., 2013). 
A meningite causada por bactérias pode ter como sintomas febre, rigidez da nuca, náusea, vômitos, fotofobia, cefaléia, agitação e convulsão (MACHADO e BORGES, 2015). O tratamento da meningite bacteriana se dá a partir da detecção do tipo da bactéria que a está causando para que possam ser recomendados antibióticos específicos a seu combate (BARCELOS, 2016).

A meningite causada por vírus pode ter seus sintomas parecidos com a meningite bacteriana, como febre, dor de cabeça, fotofobia, dor no corpo, mal-estar, alteração de consciência, pescoço rígido e convulsões (PELTON, 2010). A meningite viral não tem tratamento exclusivo porque a doença costuma desaparecer dentro de algumas semanas. O único tratamento recomendado são repouso e medicamentos para as dores e febre (BARCELOS, 2016).

O número de casos de meningite confirmados no Brasil no período de 2011 a 2015 foi de aproximadamente 88 mil casos (MORAIS et al., 2017). No ano de 2013 o país teve 18.705 casos confirmados de meningite, sendo 10.035 casos na região Sudeste, 5.583 no Nordeste, 3.461 no sul, 875 no Centro-Oeste e 751 no Norte (RODRIGUES, 2015). No ano de 2014 a região Norte teve 731 casos confirmados de meningite, sendo apenas 15 casos notificados no estado do Amapá (DIAS et al., 2017).

\section{OBJETIVO}

Mostrar o número de casos confirmados de Meningite no Brasil, quanto ao ano, região de notificação, faixa etária, sexo e raça no período de 2011 a 2015.

\section{MÉTODO}

Pesquisa realizada no banco de dados do DATASUS[8]. Foram coletados dados nacionais de acordo com as seguintes etapas: A) Acessou-se o link[9], clicou-se na aba "acesso a informação", foi-se a "sistema de informação (Tabnet)", clicou-se em "Epidemiológicas e Morbidade". Na página aberta foi-se a "Doenças e Agravos de Notificação - De 2007 em diante (SINAN)". Na próxima página selecionou-se "meningite". Na caixa "abrangência geográfica" optou-se por "Brasil por região, UF e 
município". A partir daí seguiram-se os passos para configurar as caixas "linha", "coluna" e "conteúdo": A) na linha: selecionou-se "Ano $1^{\circ}$ sintoma(s)", na coluna: "não ativa" e no conteúdo: "casos confirmados". Para esta e todas as demais seleções foram coletados dados dos anos de 2011 a 2015. B) na linha: selecionou-se "Região de notificação", na coluna: "não ativa" e no conteúdo: "casos confirmados". C) na linha: selecionou-se "Faixa Etária", na coluna: "não ativa" e no conteúdo: "casos confirmados". E) na linha: selecionou-se "Ano $1^{\circ}$ sintoma(s)", na coluna: "sexo" e no conteúdo: "casos confirmados". F) na linha: selecionou-se "Ano $1^{\circ}$ sintoma(s)", na coluna: "raça" e no conteúdo: "casos confirmados". A compilação dos dados foi feita dentro do aplicativo Excel, componente do pacote Office da Microsoft Corporation. A pesquisa bibliográfica foi realizada em artigos científicos, utilizando-se para busca computadores do laboratório de informática do Instituto Federal de Educação, Ciência e Tecnologia do Amapá, Campus Macapá, situado na: Rodovia BR 210 KM 3, s/n Bairro Brasil Novo. CEP: 68.909-398, Macapá, Amapá, Brasil.

\section{RESULTADOS}

A figura 1 mostra a porcentagem de casos confirmados de meningite no Brasil entre os anos de 2011 a 2015. Do ano de 2011 para o ano de 2012 ocorreu um pequeno aumento no número de casos. De 2013 a 2014 o número de casos apresentou uma diminuição. A maior diminuição ocorreu em 2015, quando comparado aos dois anos anteriores. 
Figura 1 Mostra a porcentagem de casos confirmados de meningite no Brasil entre os anos de 2011 a 2015.

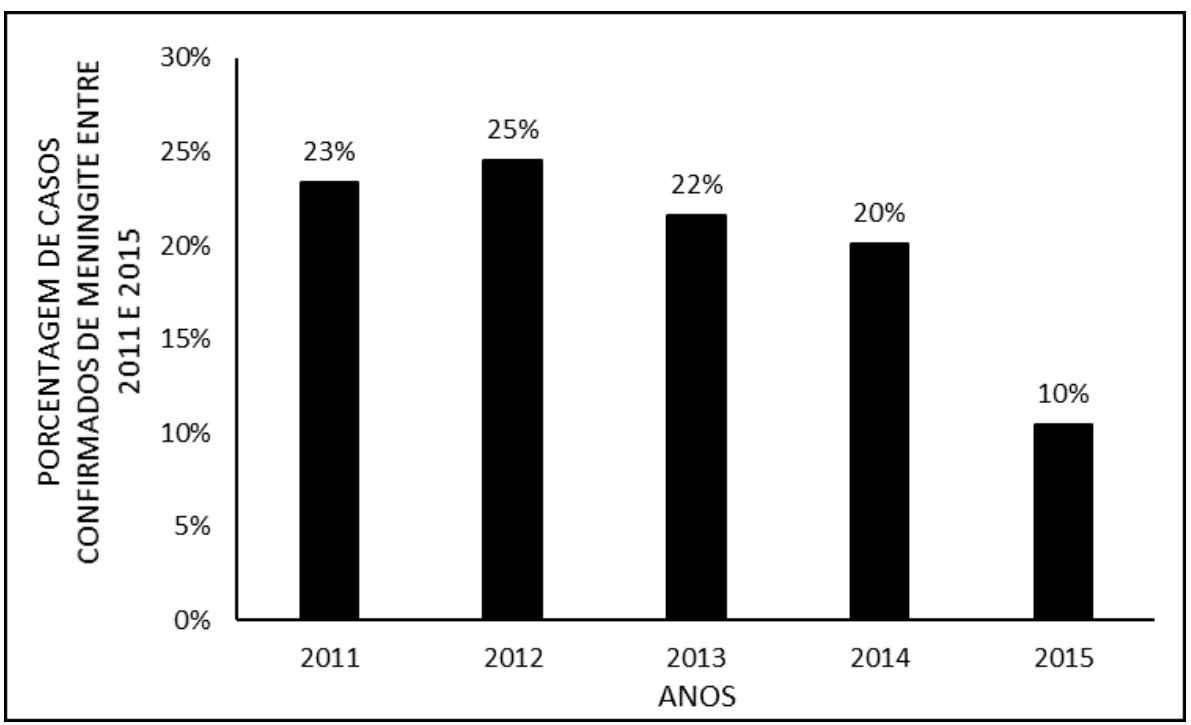

A figura 2 mostra a porcentagem de casos confirmados de meningite nas regiões do Brasil entre os anos de 2011 e 2015. A região sudeste apresenta o maior número de casos, seguida pelas regiões nordeste e sul. As duas menores porcentagens de casos confirmados ocorreram respectivamente nas regiões centro-oeste e norte.

Figura 2 Mostra a porcentagem de casos de meningite por regiões entre os anos de 2011 e 2015.

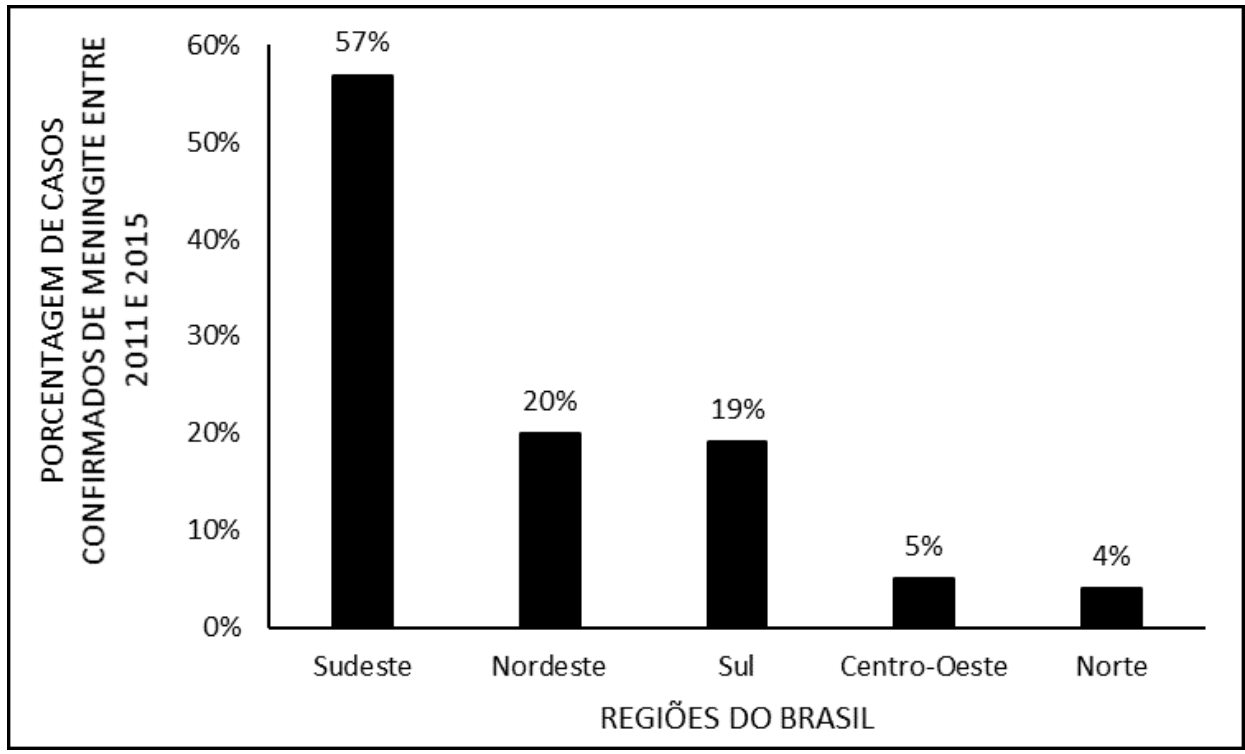


A figura 3 mostra a porcentagem de casos confirmados de meningite no Brasil por faixa etária entre os anos de 2011 a 2015. Os indivíduos de 0 a 19 anos apresentam a maior porcentagem de casos confirmados, seguido pelos indivíduos de 20 a 39 anos e 40 a 59 anos. Os grupos etários que apresentam o menor número de casos confirmados são os indivíduos de 60 a 79 anos e mais 80 anos, respectivamente.

Figura 3 Mostra a porcentagem de casos confirmados de meningite por faixa etária entre os anos de 2011 a 2015.

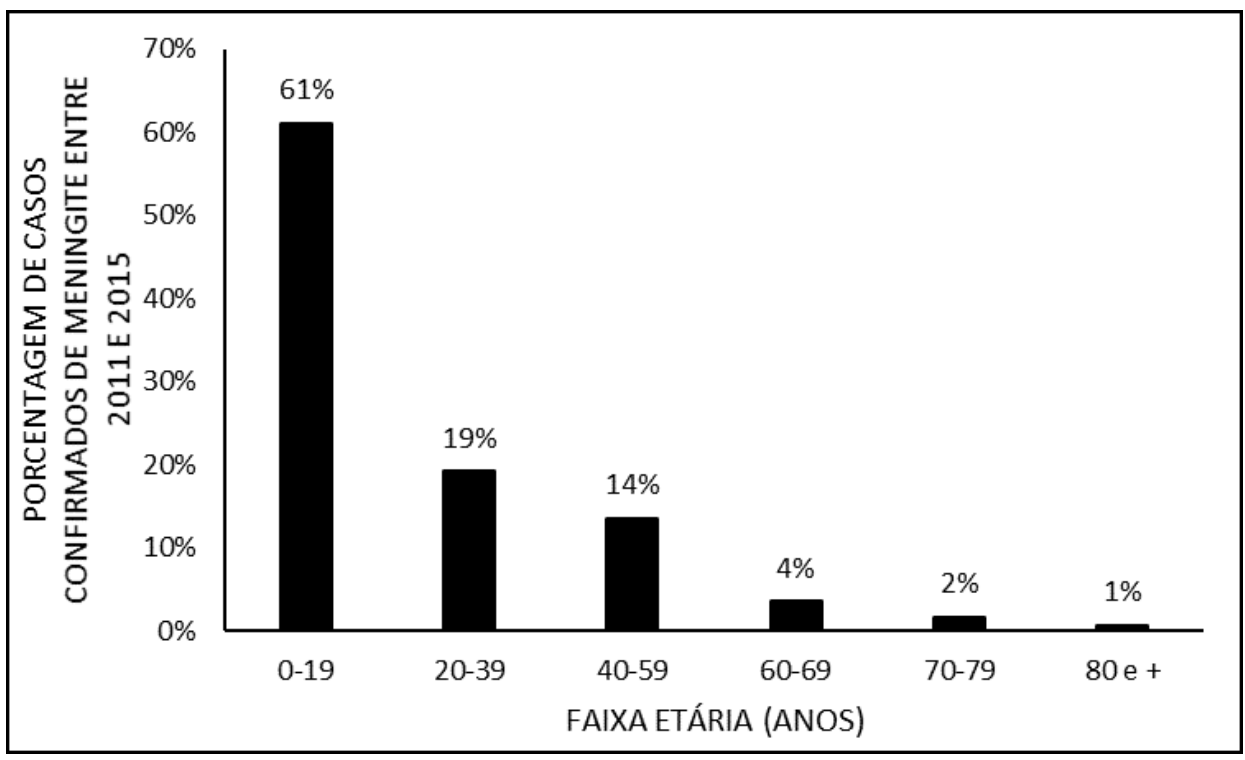

A figura 4 compara a porcentagem de casos confirmados de meningite no Brasil por gênero entre os anos de 2011 a 2015. Neste período o gênero masculino apresentou maior média do que gênero feminino. Ambos mantiveram discreta flutuação nos anos estudados. 
Figura 4 Mostra uma comparação na porcentagem de casos confirmados de meningite por gênero entre os anos de 2011 a 2015.

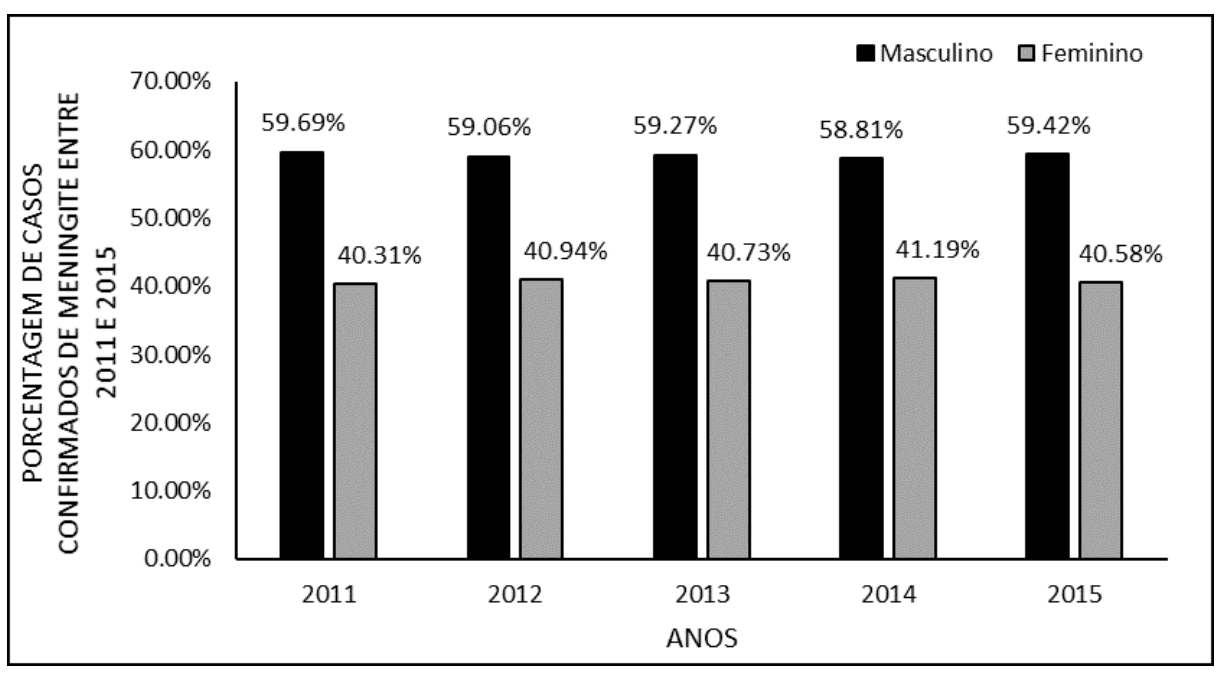

A figura 5 mostra a porcentagem de casos confirmados de meningite por evolução entre os anos de 2011 a 2015. Observamos que o número de pacientes que receberam alta é quase nove vezes maior dos que foram a óbito por meningite.

Figura 5 Mostra a porcentagem de casos confirmados de meningite por raça entre os anos de 2011 a 2015

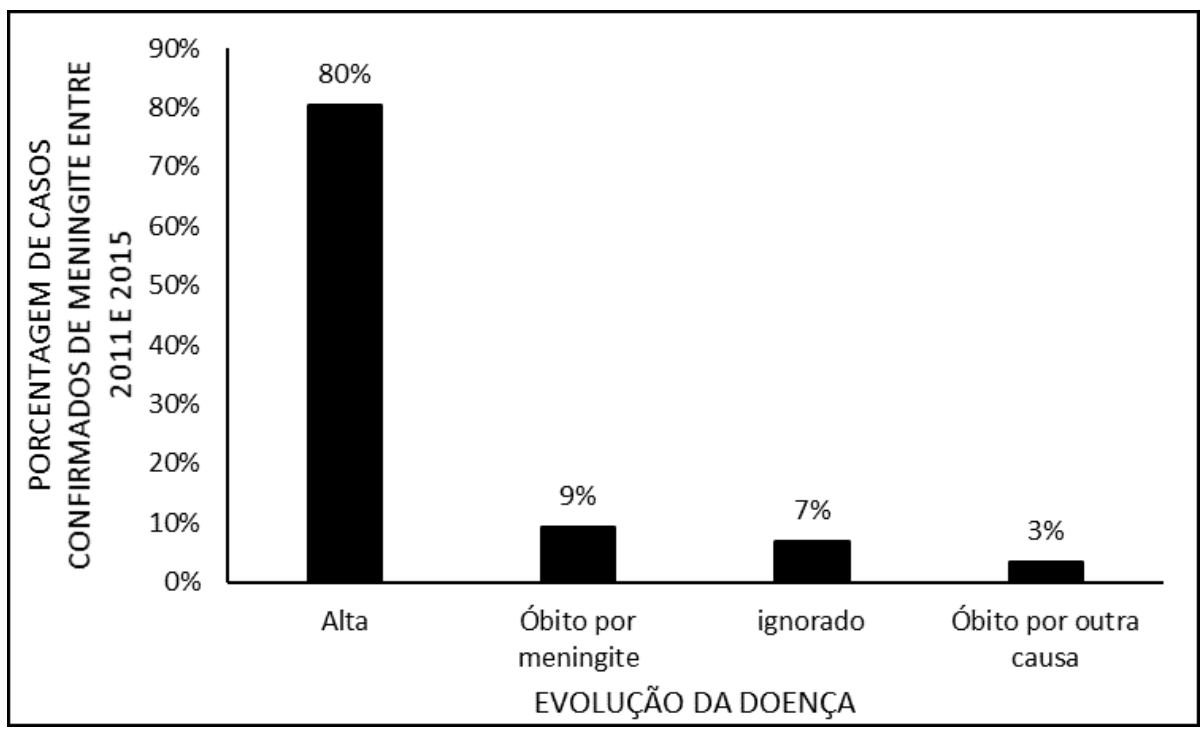

A figura 6 mostra a porcentagem de casos confirmados de meningite no Brasil por etnia (raça) entre os anos de 2011 a 2015. Os indivíduos de etnia branca apresentam RC: 49704

Disponível em: https://www.nucleodoconhecimento.com.br/saude/meningite-no-brasil 
o maior número de casos confirmados, seguidos pelos indivíduos de etnia parda. As três menores porcentagens de casos confirmados aparecem nos indivíduos de etnia preta, amarela e indígena, respectivamente.

Figura 6 Mostra a porcentagem de casos confirmados de meningite por raça entre os anos de 2011 a 2015.

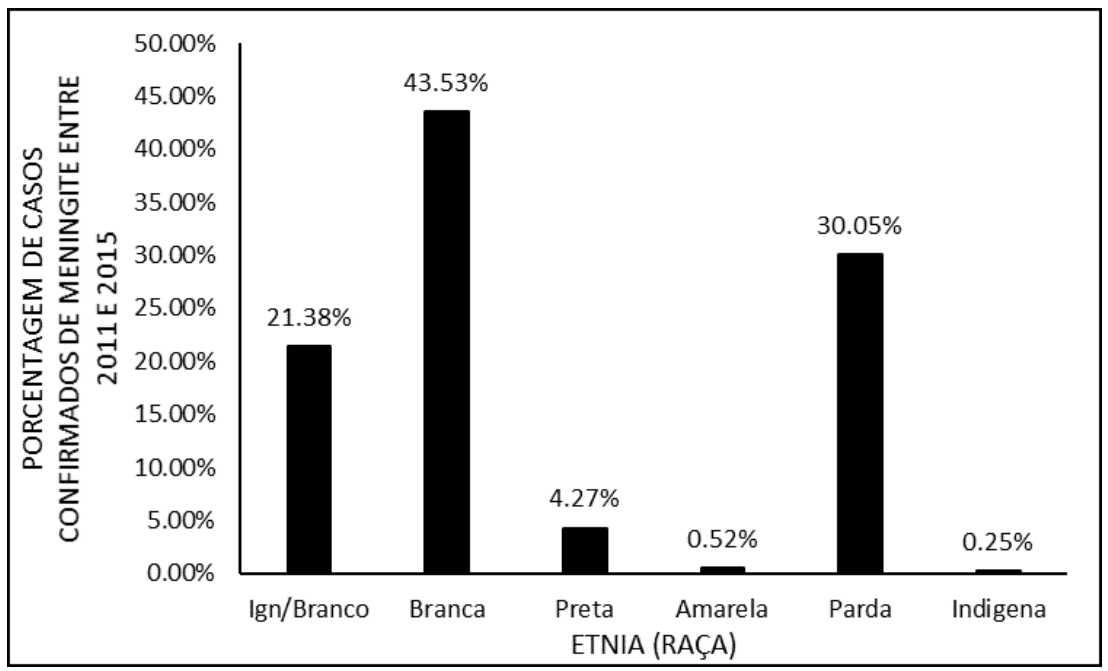

A figura 7 mostra a porcentagem de casos confirmados de meningite por zona de residência entre os anos de 2011 a 2015. A zona urbana tem maior número de infectados enquanto as zonas rural e periurbana tem porcentagens extremamente baixas.

Figura 7 mostra a porcentagem de casos confirmados de meningite por zona de residência entre os anos de 2011 a 2015.

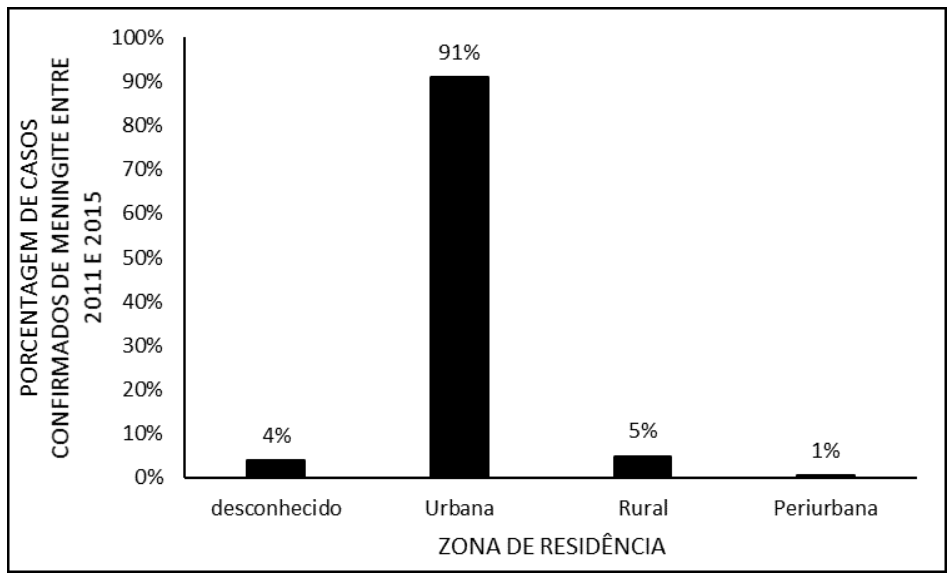

RC: 49704

Disponível em: https://www.nucleodoconhecimento.com.br/saude/meningite-no-brasil 


\section{DISCUSSÃO}

Os dados mostram uma estabilidade no número de casos de meningite no Brasil nos quatro primeiros anos estudados e uma queda no último ano (figura 1). A redução do número de casos confirmados de meningite em 2015 provavelmente foi resultado de políticas de educação de higiene e prevenções promovidas por órgãos governamentais de cada estado brasileiro. A vacinação contra a meningite tipo $B$ e a vacina $B C G$ que é aplicada ao indivíduo após o nascimento diminuiu e vem diminuindo o número de casos de meningite no Brasil (GUIMARÃES e MOREIRA, 2014; DIAS et al., 2017).

A região sudeste brasileira apresenta a maior média de casos de meningite, seguida pelas regiões nordeste e sul (figura 2). A região Sudeste apresenta a maior população do Brasil, seguida pelo Nordeste, Sul, Centro-Oeste e Norte (IBGE, 2010). A região sudeste tem maior número de casos confirmados provavelmente por ser uma das regiões mais desenvolvidas do Brasil e concentrar um grande número de indivíduos. Vivendo em uma mesma área a população compartilha o mesmo transporte coletivo e ambiente de trabalho. Isto pode fazer que a doença se espalhe mais rapidamente, afetando maior número de indivíduos (RODRIGUES, 2015).

Indivíduos de faixa etária entre 0 e 19 anos parecem ser mais afetados pela meningite (figura 3). O maior número de casos confirmados nesta faixa etária por ocorrer devido a fatores como imaturidade imunológica e agrupamento dessa população em ambientes escolares de segundo e terceiro graus (DIAS et al., 2017).

Os dados mostram que o gênero masculino apresentou mais casos de meningite que gênero feminino (figura 4). O gênero masculino se sente imune a doenças devido seu porte físico e isso faz com eles procurem menos o médico. Quando sentem sintomas de doenças normalmente retardam a ida ao médico se colocando em situações de risco e propícios a contrair doenças (SCHRAIBER et al., 2010).

A pesquisa apontou que a evolução dos casos de meningite está mais para cura do que para óbito (figura 5). O desenvolvimento das técnicas de diagnóstico e 
capacitação dos profissionais da saúde para a realização do tratamento precoce da meningite parece proporcionar maior êxito na cura da doença (RODRIGUES, 2015).

De acordo com a pesquisa feita a etnia mais afetada pela meningite foi a branca (figura 6). Os dados coincidem com a literatura, porém em alguns casos há divergência que apontam a raça negra ou parda apresenta o maior número de casos confirmados, esse conflito de dados é explicado pela mistura de etnias que a população brasileira apresenta, e isso dificulta a determinação racial da população, visto que ela é autodeclarada (MONTEIRO et al., 2014).

A pesquisa mostra que a zona urbana tem maior média de infectados por meningite (figura 7). Segundo a literatura, o maior número de casos pode estar concentrado na área urbana pela maior quantidade de indivíduos residindo nesta região. Quando se leva em conta a forma aérea de transmissão nota-se maior probabilidade de contágio em áreas mais populosas (MORAIS et al., 2017).

\section{CONCLUSÃO}

Os casos confirmados de meningite no Brasil em 2015, diminuíram devido a campanhas de prevenções e higiene promovidas pelo governo federal, com auxílio de campanhas de vacinação. O Sudeste, por ser a região mais populosa do Brasil, teve maior número de casos confirmados devido à grande concentração de indivíduos que convivem nos mesmos ambientes dentro da sociedade. Isso faz o agente causador da doença se espalhe de maneira mais dinâmica. As crianças e jovens foram as pessoas mais afetadas pela meningite por ficarem em um grande período de tempo dentro de ambientes escolares com grande aglomeração de indivíduos. Os homens são mais afetados pela meningite por terem menos cuidado com sua saúde. O diagnóstico imediato da meningite e médicos capacitados aumentam a possibilidade de cura dos indivíduos infectados. Devido a dificuldades na caracterização racial dentro do território brasileiro e por conta da miscigenação existe alternância entre pessoas brancas com meningite e pessoas negras ou pardas. A zona urbana é mais atingida por ter mais pessoas residindo nessa região o que facilita a transmissão da meningite. 


\section{REFERENCIAS}

BARCELOS, A. L. M. Ferritina Liquórica no Diagnóstico Etiológico de Meningites em Pediatria. 2016. 62p. (Doutorado). Faculdade de Medicina da PUCRS, Porto Alegre RS.

DIAS, F. C. F. et al. Meningite: Aspectos Epidemiológicos da Doença na Região Norte do Brasil. Revista de Patologia do Tocantins, v. 4, n. 2, p. 46-49, 2017.

GUIMARÃES, I. L. B.; MOREIRA, A. C. A. Perfil epidemiológico da meningite em crianças. RENOME, v. 3, n. 1, p. 1 - 7, 2014.

IBGE. Censo Demográfico 2010. 2010. Disponível em: < http://www.censo2010.ibge.gov.br/sinopse/index/php?uf=29\&dados=10 >. Acesso em: 14 set. 2017.

MACHADO, C. F. T.; BORGES, B. L. C. Meningite Bacteriana na Unidade de Terapia Intensida; um Protocolo de Cuidados de Enfermegem. UNICIÊNCIAS, v. 19, p. 7985, 2015.

MONTEIRO, L. F. et al. Vigilância clínico-epidemiológica das meningites em um hospital do sul de Santa Catarina, no período entre 2007 a 2013. Arq Catarin Med., v. 43, n. 4, p. 24-29, 2014.

MORAIS, J. M. R. et al. Retrato Da Meningite Em Salvador-BA: Análise do Período entre 2011-2015. Revista Eletrônica da FAINOR, v. 10, n. 1, p. 185-196, 2017.

PELTON, S. I. Meningococcal disease awareness: clinical and epidemiological factors affecting prevention and management in adolescents. Journal of Adolescent Health, v. 46, p. S9-S15, 2010.

POBB, K. et al. Aspectos epidemiológicos e influência de variáveis climáticas nos casos notificados de meningite em crianças no municipio de ponta grossa - PR, 20022011. Revista Brasileira de Climatologia, v. 13, p. 202 - 213, 2013. 
RODRIGUES, E. M. B. Meningite: Perfil Epidemiológico da Doença no Brasil nos Anos de 2007 A 2013. 2015. 16p. (Graduação). UniCEUB

SCHRAIBER, L. B. et al. Necessidades de saúde e masculinidades: atenção primária no cuidado aos homens. Cad. Saúde Pública, v. 26, n. 5, p. 961-970, 2010.

\section{APÊNDICE - REFERÊNCIAS DE NOTA DE RODAPÉ}

7. http://datasus.saude.gov.br/

8. http://datasus.saude.gov.br/

9. datasus.saude.gov.br

Enviado: Maio, 2020.

Aprovado: Maio, 2020. 